\title{
Nrf2-driven CD36 and HO-1 gene expression in circulating monocytes correlates with favourable clinical outcome in pregnancy-associated malaria
}

Agnès Aubouy ${ }^{1 *}$, David Olagnier ${ }^{1,4}$, Gwladys Bertin², Sem Ezinmegnon ${ }^{3}$, Clarisse Majorel ${ }^{1,5}$, Saliha Mimar ${ }^{1}$, Achille Massougbodji ${ }^{3}$, Philippe Deloron ${ }^{2}$, Bernard Pipy ${ }^{1}$ and Agnès Coste ${ }^{1}$

\begin{abstract}
Background: Pregnancy-associated malaria (PAM) constitutes one of the most severe forms of malaria infection leading to fetal growth restriction and high risk of infant death. The severity of the pathology is largely attributed to the recruitment of monocytes and macrophages in the placenta which is evidenced by dysregulated inflammation found in placental blood. Importantly, $\mathrm{CD}^{+}{ }^{+}$monocytes/macrophages are also thought to participate in the tight control of the pro- and anti-inflammatory responses following Plasmodium detection through elimination of apoptotic cells and malaria-infected erythrocytes, internalization and recycling of oxidized forms of low-density lipoprotein and collaboration with TLR2 in pro-inflammatory response. Interestingly, previous work demonstrated that CD36 expression was upregulated on inflammatory macrophages following stimulation of the Nrf2 transcription factor, whilst the PPAR $\gamma$ pathway was inhibited and non-functional in the same inflammatory conditions. This current study examined the possible role of Nrf2-driven gene expression, CD36 and Haem-Oxygenase-1 (HO-1), in PAM clinical outcomes.
\end{abstract}

Methods: Clinical data and biological samples including peripheral blood mononuclear cells were collected from 27 women presenting PAM. Polychromatic flow cytometry was used to characterize innate immune cell subpopulations and quantify CD36 protein expression level on monocytes. mRNA levels of CD36, PPAR $\gamma$, Nrf2 and HO-1 were determined by qPCR and related to clinical outcomes. Finally, the capacity of monocytes to modulate CD36 expression upon rosiglitazone or sulforaphane treatment, two respective PPAR $\gamma$ or Nrf2 activators, was also investigated.

Results: The CD36 receptor, mostly expressed by CD14 ${ }^{+}$circulating monocytes, statistically correlated with increased infant birth weights. Interestingly, mRNA levels of the transcription factor Nrf2 and the enzyme HO-1 also correlated with lower parasitaemia and increased infant birth weight, while PPARy mRNA levels did not. Finally, monocytes isolated from low infant birth weight pregnant women were capable of up-regulating CD36 via the Nrf2 pathway ex vivo.

Conclusions: Altogether these results suggest that Nrf2-driven CD36 and HO-1 expression on innate immune cells could contribute to a protective and detoxifying mechanism during PAM. More powered and mechanistical studies are however needed to strengthen the conclusions of this study.

Keywords: Pregnancy-associated malaria, Clinical outcomes, Monocytes, CD36, Nrf2, HO-1

\footnotetext{
*Correspondence: agnes.aubouy@ird.fr

${ }^{1}$ Institut de Recherche pour le Développement (IRD), Université Paul

Sabatier Toulouse III, UMR 152 Pharma-Dev, CHU Rangueil, Bâtiment L1, 1

Avenue du Pr Jean Poulhès, 31059 Toulouse, France

Full list of author information is available at the end of the article
}

\section{Biomed Central}

(C) 2015 Aubouy et al. This article is distributed under the terms of the Creative Commons Attribution 4.0 International License (http://creativecommons.org/licenses/by/4.0/), which permits unrestricted use, distribution, and reproduction in any medium, provided you give appropriate credit to the original author(s) and the source, provide a link to the Creative Commons license, and indicate if changes were made. The Creative Commons Public Domain Dedication waiver (http://creativecommons.org/ publicdomain/zero/1.0/) applies to the data made available in this article, unless otherwise stated. 


\section{Background}

Each year, more than 125 million pregnant women are at risk of pregnancy-associated malaria (PAM), a severe form of malaria infection that affects both mothers and infants, causing maternal anaemia, pre-term delivery, fetal growth restriction and a higher risk of infant death $[1,2]$. The severity of the pathology is attributed to the sequestration of Plasmodium falciparum-infected erythrocytes $(P f$-iE) in placental intervillous blood spaces that leads to the recruitment of monocytes and macrophages to the placenta $[3,4]$. Several studies have demonstrated a link between monocyte/macrophage recruitment and adverse outcomes such as low birth weight and maternal anaemia, but also functional damage to placental villi and disturbances to feto-maternal exchanges [4-7]. The mechanisms proposed imply monocyte/macrophage activation which is evidenced by high levels of proinflammatory cytokines in placental blood [8-11].

On the other hand, it is largely accepted that monocyte and macrophage infiltrates might also have a beneficial role in defence mechanisms, such as non-opsonic CD36-dependent phagocytosis, antibody-dependent cellular inhibition (ADCI), opsonic phagocytosis and the production of cytokines that direct both cellular and humoral immunity $[12,13]$. CD36, a membrane glycoprotein present on many mammalian cells types, including monocyte/macrophages, is a multifaceted receptor that displays an impressive range of functions [reviewed in 14]. On monocyte/macrophages, CD36 acts as a scavenger receptor to protect the host from inflammation through phagocytosis of apoptotic cells (efferocytosis) and diverse pathogens including $P f$-iE. The initial sensing of the invading malaria parasite is mediated through recognition of highly conserved microbial structures by pattern-recognition receptors (PRRs) expressed on monocytes and macrophages $[12,15]$. The CD36 scavenger receptor, a PRR, is known for its involvement in recognizing and internalizing non-opsonized $P f$-iE, in a non pro-inflammatory manner. Indeed, macrophages from CD36 knock-out mice were shown to engulf significantly less iEs than macrophages from CD36 wild-type mice, and displayed earlier peaks of parasitaemia, higher parasite densities and mortality rates [16-18]. CD36 also contributes in the internalization and the recycling of oxidized forms of low-density lipoprotein (oxLDL) [14]. In complement with its phagocytic activities, CD36 is also known to contribute to the regulation of the inflammatory response through cooperation with TLR2 [19]. CD36 and TLR2 collaboration leads to a pro-inflammatory response via ERK, p38, MAPK, JNK and NF-kB signaling following interaction with malaria-GPI anchors $[19,20]$. On endothelial cells, CD36 is known for its role as a negative regulator of angiogenesis and has also been identified as a sequestration receptor for $P f$-iE during malaria [21], although the main sequestration receptor during PAM is chondroitin sulfate A (CSA) [22]. Even though $P$. falciparum parasites infecting pregnant women are known to predominantly display CSA-adherent phenotype and low adhesion to CD36 [23], the multifaceted roles of CD36 have prompted us to examine the possible involvement that this receptor may play in PAM clinical outcomes.

CD36 expression is under the transcriptional control of the peroxisome proliferator-activated receptor gamma $(\operatorname{PPAR} \gamma)$ and the nuclear factor erythroid-derived 2-like 2 (NF-E2L2 or Nrf2) [24, 25]. During malaria blood stage infection, haemoglobin metabolism by the parasite leads to reactive oxygen species (ROS) production that activates the transcription factors PPAR $\gamma$ and Nrf2 [26-28]. Importantly, it was demonstrated in vitro that human and murine macrophages downregulated CD36 expression in the presence of TNF, due to a failure to express and activate PPAR $\gamma$ [29]. However, unlike PPAR $\gamma$ agonists, Nrf2 activators maintained their capacity to enhance CD36 expression and CD36-mediated phagocytosis in inflammatory conditions [29]. During PAM, elevated pro-inflammatory cytokines are consistently found, particularly TNF, IFN $\gamma$ and MCP-1 [8, 9], suggesting a possible impairment of the PPAR $\gamma$ pathway. Furthermore, the activation of the nuclear factor Nrf2 constitutes a key mechanism in the antioxidant defence response used by host cells during infection [30]. Among the hundreds of Nrf2-regulated genes, the enzyme haem oxygenase-1 (HO-1) is certainly one of the most important and was identified as a crucial detoxifier of free haem during malaria infection [31]. The role of HO-1 during malaria is however controversial and requires a better understanding. The protective role of HO-1 and carbon monoxide against cerebral malaria development in mice was previously demonstrated [32, 33], whereas other groups reported that high $\mathrm{HO}-1$ was a risk factor for severe or cerebral malaria in African children [34, 35]. The detoxifying function of HO-1 is also closely related to another scavenger receptor, CD163, that binds the haptoglobinhaemoglobin complex, removes it from circulation by endocytosis, allowing subsequent degradation of haem by $\mathrm{HO}-1$ [36]. Few reports have investigated CD163 as a biomarker during malaria, although it may constitute an important factor implied in the anti-inflammatory response.

To date, no study has demonstrated that monocytes/ macrophages can contribute to malaria protection during pregnancy. Here, monocytes sampled from women presenting PAM at delivery in Benin (West Africa) 
were studied. The objective was to examine whether the expression of both CD36 and HO-1 by monocytes plays a role in clinical outcomes during PAM, based on the following hypothesis: (1) the scavenger receptor CD36 may be involved in the pro- and anti-inflammatory response, and to a lesser extent the elimination of $P f$-iE during PAM; and (2) in a PAM context, the Nrf2 pathway may play an important role, both for its maintenance of CD36 expression and for its capacity to modulate the expression of detoxifying enzymes including HO-1. This study demonstrates that CD36 expression is directly correlated to higher infant birth weights. Furthermore, the importance of the Nrf2 pathway was also shown by an inverse relationship between Nrf2 mRNA levels and parasitaemia, and a positive correlation between HO-1 mRNA and a higher infant birth weight. Finally, CD36 expression on monocytes from mothers with low birth weights infants could be increased following Nrf2 stimulation, but not PPAR $\gamma$. Altogether these results suggest that Nrf2-driven CD36 and HO-1 expression on innate immune cells could contribute to a protective and detoxifying mechanism during PAM.

\section{Methods}

\section{Patients and ethical statement}

Patient enrolment and ethical statement are described elsewhere [37]. Briefly, ethical clearance was obtained from the Institutional Ethics Committee of the Faculté des Sciences de la Santé at the Abomey Calavi University in Benin. Pregnant women were enrolled in Cotonou, southern Benin, in the Mother and Child Hospital (Hôpital de la Mère et de l'Enfant Lagune). Inclusion criterion was a positive diagnosis for $P$. falciparum infection at delivery. Parasitaemia was retrospectively quantified through Giemsa-stained thick blood smears prepared from peripheral blood and through placental impression smears.

\section{Clinical outcomes}

Two clinical outcomes were studied: parasitaemia and infant birth weight. Both placental and peripheral parasitaemia were analysed, respectively named "P" and "pP". As $1 \%$ parasitaemia and $2500 \mathrm{~g}$ for infant birth weight (BW) are standard thresholds in clinical malaria studies, both thresholds were considered (P or pP $>1 \%$ and $\mathrm{BW}$ $\leq 2500 \mathrm{~g}$ ) to define adverse outcomes.

\section{Blood sampling and PBMC isolation}

Peripheral venous blood was collected from all patients in a vacutainer tube containing EDTA and processed within $4 \mathrm{~h}$. Plasma was sampled after centrifugation and stored at $-20{ }^{\circ} \mathrm{C}$. Human peripheral blood mononuclear cells (PBMC) were isolated by a density gradient centrifugation method on Lymphoprep (Abcys, France).

\section{TNF and IL-10 plasma titration}

The levels of TNF and IL-10 in plasma samples were determined using a commercially available OptiEIA kit (BD Biosciences) as per manufacturer's instructions.

\section{Flow cytometric analysis}

Peripheral blood mononuclear cells were stained with CD14-PerCp, CD16-FITC (Immunotech), and CD36APC (BD Pharmingen) antibodies during $15 \mathrm{~min}$ in the dark for monocyte identification. A minimum of 5000 cells were analysed for each data point. Acquisitions were performed on a FACScalibur using CellQuestPro software (Becton Dickinson, France). Forward and side scattering parameters (FSC and SSC) were first used to gate on monocytes among other leucocytes. Three CD14 CD16 monocytes subsets were defined according to antiCD14 and anti-CD16 labeling (see Fig. 1).

\section{Monocyte activation and mRNA expression measurements by RT-qPCR}

Monocytes were isolated by adherence to plastic for $1 \mathrm{~h}$ $30 \mathrm{~min}$ in M-SFM (Gibco Invitrogen) at $37^{\circ} \mathrm{C} 5 \% \mathrm{CO}_{2}$. After several washes in pre-warmed PBS, monocytes were incubated during four additional hours in separate wells with $1 \mu \mathrm{M}$ rosiglitazone (Cayman Chemical), $1 \mu \mathrm{M}$ sulforaphane (Sigma Aldrich), or with medium alone (control wells). Cells were prepared for RNA extraction with the RNAqueous ${ }^{\circledR}$-Micro Kit (Ambion, Life Technologies), as described by the supplier. Synthesis of cDNA was performed from a minimum of 100 ng of total RNA with Verso cDNA Synthesis Kit (Thermo Scientific) according to the manufacturer's recommendations and primed with anchored oligo-dT. Quantitative real-time PCR was performed on a LightCycler 480 system using LightCycler 480 SYBR Green I Master (Roche Diagnostics). Serially diluted samples of pooled cDNA were used as external standards in each run for the quantification and results were expressed in fold induction relative to the respective control. The amplifications were performed for 60 cycles $(10 \mathrm{~s}$ at $95{ }^{\circ} \mathrm{C}$ and $60 \mathrm{~s}$ at $60{ }^{\circ} \mathrm{C}$ ) but the numbers of cycles needed for amplification (Cp) for all the genes tested was between $15(18 \mathrm{~S})$ and $35(\operatorname{PPAR} \gamma)$. The primers (at a final concentration of $10 \mathrm{mM}$ ) were designed using Primer 3 software, and are listed in Additional file 1: Table S1. Human 18s mRNA was used as the invariant control. 


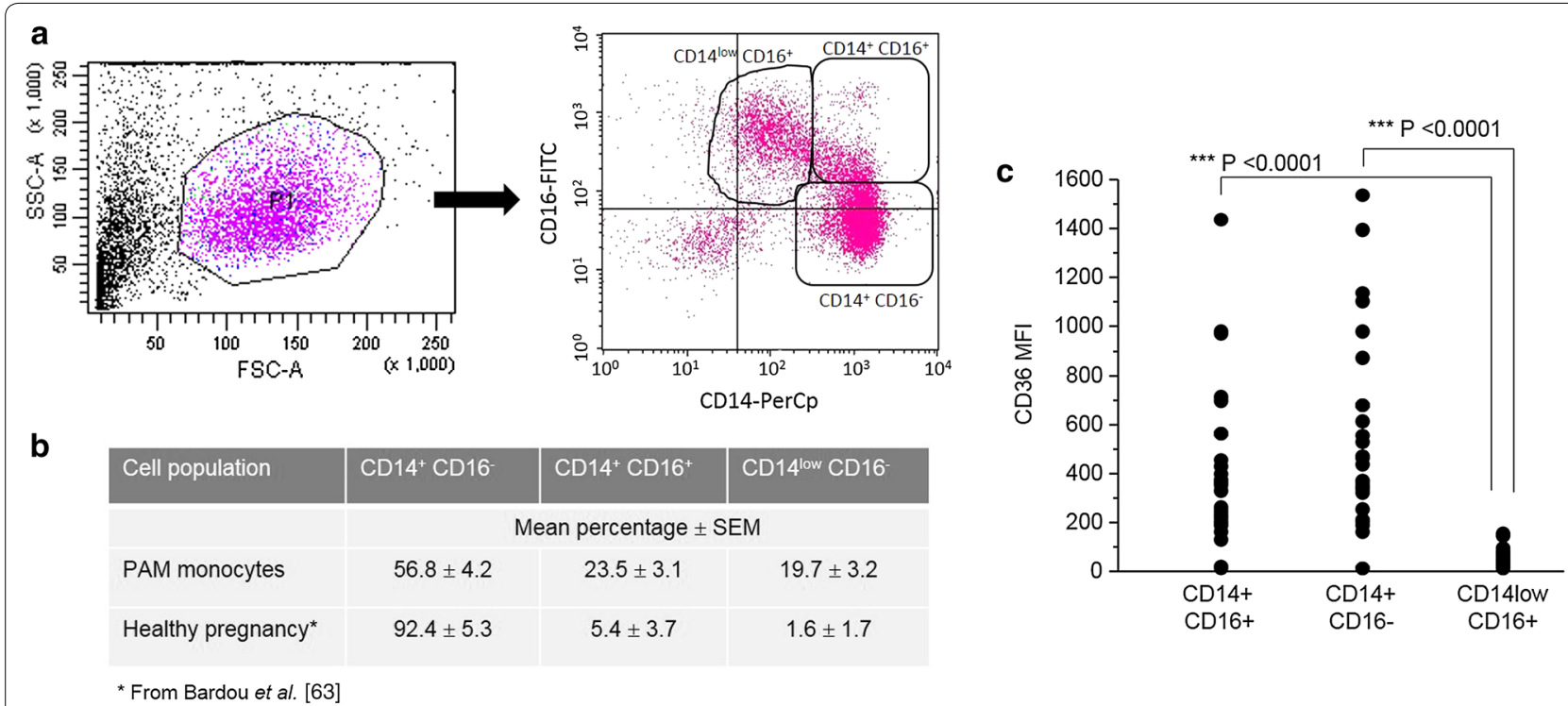

Fig. 1 Relations between PAM, monocyte sub-populations and CD36 expression. a Gating strategy for the identification of monocyte sub-populations. Forward and side scattering parameters (FSC and SSC) were first used to gate monocytes among other leucocytes. Monocytes were subdivided into $\mathrm{CD}_{14}{ }^{+} \mathrm{CD} 16^{-} / \mathrm{CD} 14^{+} \mathrm{CD} 16^{+} / \mathrm{CD} 14^{\text {low }} \mathrm{CD} 16^{+}$, according to $\mathrm{CD} 14$ and $\mathrm{CD} 16$ staining characteristics. Plots shown are representative examples. b Percentages of each monocyte sub-set found in PAM monocytes. $\mathbf{c}$ CD36 protein expression according to monocyte sub-populations in PAM. Geometric mean fluorescence intensity (MFI) was measured by flow cytometry for each monocyte sub-set. Values were compared by the Mann-Whitney U-test

\section{Statistical analysis}

All statistical analyses were carried out with non-parametric tests and performed with the software Statview. The Wilcoxon rank test was used to compare the distribution of continuous values. Values were compared according to categorized variables (birth weight, parasitaemia, clinical outcome, plasma TNF and IL-10 levels, CD36 protein expression level) by Mann-Whitney U-test, twofactor covariance analysis (ANOVA) and Kruskal-Wallis test. The Spearman correlation test was used to test the relation between continuous variables.

\section{Results}

\section{Clinical, parasitological and biological data}

Table 1 represents general clinical and parasitological data obtained from the pregnant women included in the study. Low birth weight was neither associated with age, gravidity, parasitaemia, nor cytokine levels. Women that displayed a peripheral parasitaemia $\geq 1 \%$ were younger with a lower gravidity, higher prevalence of placental parasitaemia and increased IL-10 plasma levels. Placental parasitaemia was overall higher than peripheral parasitaemia (Wilcoxon rank test, $\mathrm{P}=0.02$ ). No adverse

Table 1 Clinical, parasitological and plasma cytokine levels of pregnant women

\begin{tabular}{lccc}
\hline & All $(\mathbf{N}=\mathbf{2 5})$ & $\mathbf{B W} \leq \mathbf{2 . 5} \mathbf{k g}(\mathbf{N}=\mathbf{5})$ & $\mathbf{P} \geq \mathbf{1} \mathbf{\%}(\mathbf{N}=\mathbf{8})$ \\
\hline Age (years) & $25(22-30)$ & $25(21-37)$ & $22(20-23)^{* *}$ \\
Gravidity & $2.0(2.0-3.5)$ & $2.0(2.0-6.0)$ & $2.0(1.0-2.0)^{*}$ \\
Birth weight $(\mathrm{kg})$ & $2.8(2.5-3.1)$ & $2.0(1.7-2.2)^{* *}$ & $2.8(2.6-3.2)$ \\
P (\%) & $0.05(0.01-3.5)$ & $0.03(0.02-2.9)$ & $6.0(4.1-10.8)^{* * *}$ \\
PP $(\%)$ & $1.0(0.07-13.5)$ & $0.1(0.06-12.4)$ & $2.9(2.8-3.4)$ \\
TNF $(\mathrm{pg} / \mathrm{mL})$ & $0(0-0.8)$ & $0(0-12.2)$ & $0(3.7-59.0)^{*}$ \\
IL-10 $(\mathrm{pg} / \mathrm{mL})$ & $0(0-186)$ & $111(14-226)$ & $2.2(0.03-8.7)$ \\
\hline
\end{tabular}

Data are presented in medians (interquartile range)

Data were compared according to the clinical criteria defined ( $\mathrm{BW} \leq 2.5 \mathrm{~kg}$ versus $\mathrm{BW}>2.5 \mathrm{~kg}, \mathrm{P}<1 \%$ versus $\mathrm{P} \geq 1 \%$, $\mathrm{pP}<1 \%$ versus $\mathrm{pP} \geq 1 \%$ ) by Mann-Whitney U-test

$P$ peripheral parasitaemia, $p P$ placental parasitaemia

${ }^{*} P<0.05,{ }^{* *} P<0.005$, *** $P<0.0005$ 
outcome was reported in the group of pregnant women following delivery, apart from the low birth weight.

\section{CD14 CD16 monocyte sub-populations differ by their levels of CD36 protein expression}

Human monocytes were classified based on CD14 and CD16 expression in a major classical sub-population $\left(\mathrm{CD} 14^{+} \mathrm{CD}^{-} 6^{-}\right)$, and two minor sub-populations, intermediate $\left(\mathrm{CD}_{14}{ }^{+} \mathrm{CD} 16^{+}\right)$and non-classical monocytes $\left(\mathrm{CD} 14^{\text {low }} \mathrm{CD} 16^{+}\right)$[38]. Polychromatic flow cytometry analysis was used to precisely identify the monocyte subsets based on CD14 and CD16, and determine their expression of CD36 (Fig. 1a). The mean percentages $( \pm$ SEM) of each monocyte subset was $56.8 \%( \pm 4.2)$ $\mathrm{CD}_{14}{ }^{+} \mathrm{CD} 16^{-}, 23.5 \%( \pm 3.1) \mathrm{CD} 14^{+} \mathrm{CD} 16^{+}$and $19.7 \%$ $( \pm 3.2) \mathrm{CD}^{\text {low }} \mathrm{CD}^{+}$(Fig. 1b). As shown in Fig. 1c, CD36 protein expression was similar between the CD14 ${ }^{+}$ $\mathrm{CD}_{16}{ }^{-}$and $\mathrm{CD} 14^{+} \mathrm{CD} 16^{+}$subsets but significantly reduced in $\mathrm{CD} 14^{\text {low }} \mathrm{CD} 16^{+}$monocytes (Mann-Whitney U-test, $\mathrm{P}<0.0001)$.

\section{CD36 mRNA and protein expression levels correlate with increased birth weight}

To evaluate the implication of the CD36 receptor on circulating monocytes during PAM, the relationship between clinical parameters and its expression level was analysed. As the number of pregnant women included in the study was relatively low $(n=27)$, it reduces the power of the statistical tests used. Thus, two complementary statistical approaches were used to consolidate the results, the two-factor covariance analysis (ANOVA) and the Spearman correlation test (see Fig. 2). High CD36 protein expression levels statistically correlated with increased birth weight according to both tests (Fig. 2a, b, $\mathrm{P} \leq 0.05)$. CD36 mRNA levels also positively correlated with infant birth weight by the Spearman test (Fig. 2d, $\mathrm{P}<0.05$, Fig. $2 c, \mathrm{P}>0.05)$. No other significant relationships were found with the other recorded clinical parameters. These results demonstrate that CD36 expression on monocytes was positively associated with an important and favourable clinical outcome for PAM.

\section{High Nrf2 and HO-1 mRNA levels correlate with low parasite density and high infant birth weight}

To further the analysis carried out on CD36, the study focused on the different transcription factors regulating CD36 expression on monocytes. The transcriptional regulation of CD36 is known to involve both the PPAR $\gamma$ and Nrf2 transcription factors [24, 25]. HO-1 mRNA levels were also examined, as its gene regulation directly depends upon Nrf2 activation. CD36, PPAR- $\gamma$, Nrf2 and HO-1 mRNA levels were all highly correlated with each other. Specifically, CD36 and PPAR- $\gamma$ were strongly correlated with each other and Nrf2 and HO-1 $[\mathrm{P}<0.0001$ by the Spearman test, correlation coefficient (rho) $=0.71-0.84]$. Nrf2 and HO-1 were similarly well correlated $(\mathrm{P}<0.001$, rho $=0.56)$ (Fig. 3). The potential link between these factors and various clinical features associated with PAM was investigated. Nrf2 mRNA levels were higher in monocytes from pregnant women presenting peripheral or placental parasitaemia $<1 \%$ (Fig. 4a, b). Additionally, higher levels of HO-1 mRNA were linked with increased infant birth weight (Fig. 4c). No clinical features were found to be associated with PPAR $\gamma$ (see Fig. 4a, b). These results outline the potential beneficial role of the Nrf2/HO-1/CD36 axis on PAM clinical outcomes.

\section{Nrf2 activation can restore CD36 levels in monocytes from mothers with low birth weight children}

To assess the capacity of monocytes from PAM patients to modulate CD36, the mRNA level of CD36 upon rosiglitazone or sulforaphane treatment, two respective PPAR $-\gamma$ and Nrf2 inducers, was measured. Furthermore, the level of gene induction was also compared between mothers who bore infants with low (MoLBW) and high (MoHBW) birth weights. Interestingly, MoLBW displayed significant increases in CD36 transcription following sulforaphane treatment compared to MoHBW (Fig. 5, Mann-Whitney U-test, $\mathrm{P}=0.005$ ). It is important to note here that the maximum level of CD36 mRNA did not differ between the two groups, and that the increase was due to a low basal level of CD36 in the MoLBW. Rosiglitazone treatment failed to induce CD36 mRNA induction in both groups of women.

\section{CD36, Nrf2, PPAR $\gamma$ and HO-1 mRNA levels were higly corelated to anti-inflammatory markers IL-10 and CD163} The relationship between anti-inflammatory markers and CD36 expression was examined, as well as PPAR $\gamma, \mathrm{Nrf} 2$ and HO-1. As shown in Fig. 6, CD36, PPAR $\gamma, \mathrm{Nrf} 2$ and HO-1 mRNA levels were all positively correlated with IL-10 (Fig. 6a) and CD163 mRNA levels (Fig. 6b) (Spearman correlation test, $\mathrm{P}<0.005$ to $\mathrm{P}<0.0001)$. CD163 and IL-10 were also highly related (Fig. 6a).

\section{Discussion}

Monocyte/macrophage accumulation in placental blood intervillous spaces during PAM is widely associated with poor clinical outcome [4-6]. The objective of this study was to examine the role of the monocyte/macrophage receptor $\mathrm{CD} 36$ and the detoxifying enzyme $\mathrm{HO}-1$ during PAM. In this study, monocytes from Beninese pregnant women infected with malaria at delivery were studied. A total of 27 pregnant women were included in the study and subdivided into two groups based on the birth 

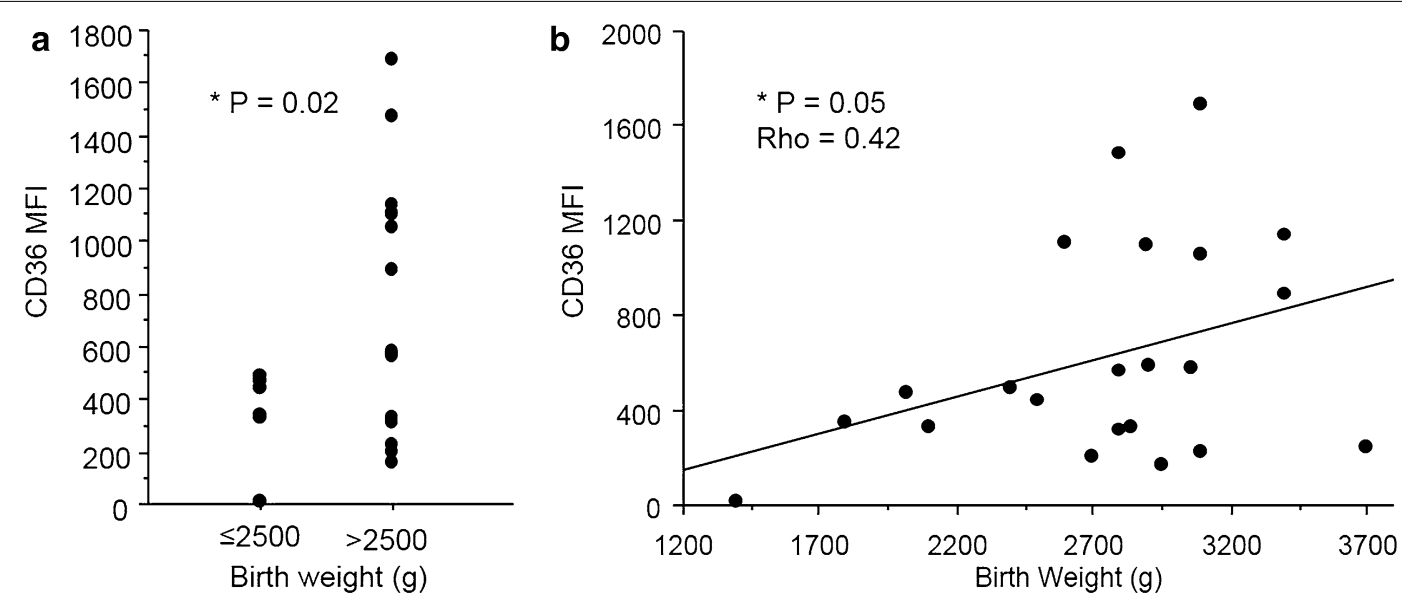

C

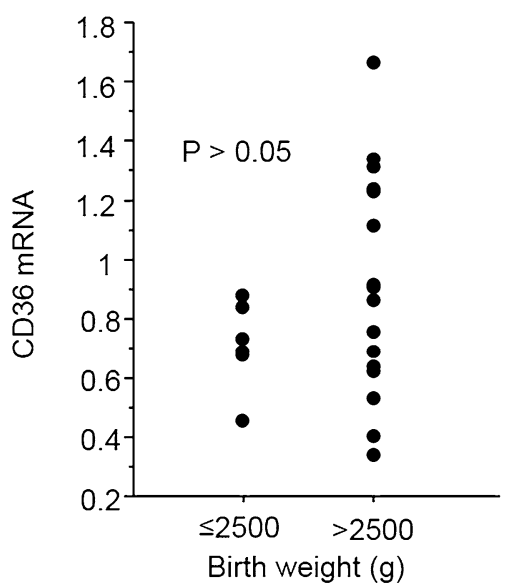

d

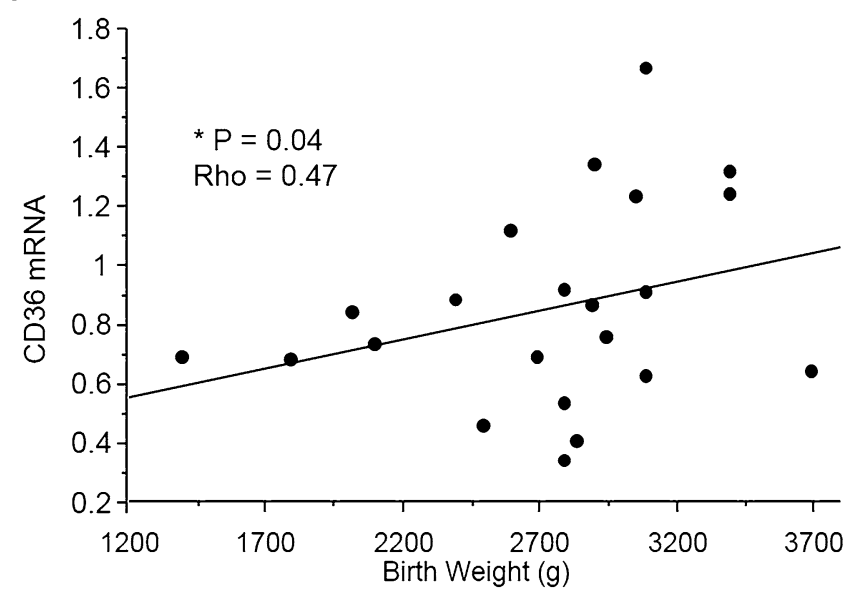

Fig. 2 Relation between CD36 protein and mRNA expression and birth weight in PAM. a, c CD36 MFI and mRNA expression levels were compared according to birth weight threshold of $2.5 \mathrm{~kg}$, by the two-factor covariance analysis (ANOVA). b, d CD36 MFI and mRNA expression levels were positively related to birth weight values by the Spearman correlation test

weight of their infants. For the first time, a correlation between Nrf2-driven CD36 and HO-1 gene expression on circulating monocytes and a positive outcome during PAM was demonstrated on clinically relevant samples. While the low number of MoLBW $(n=5)$ is a limitation, the use of multiple and complementary statistical tests helps to validate and strengthen the findings. More statistically powered studies will be needed to explore possible mechanisms.

Low infant birth weight constitutes one of the main adverse outcome for PAM, due to restricted growth during pregnancy and to placental circulation disturbances [39], for which there are two non-excluding hypotheses. One is based on impaired uterine artery remodeling which leads to the release of pro-inflammatory cytokines that cause hemodynamic disturbances in the utero placental circulation [40]. The other is based on mechanical obstruction of the intervillous spaces due to infected erythrocytes and monocytes, and fibrin deposition [41]. The present report supports the second hypothesis, as the involvement of CD36 implicates the elimination of $P f$-iE and apoptotic cells which would likely contribute to the removal of any obstructions in the intervillous spaces. However, the CD36 adhesion phenotype is not a common feature of malaria, as placenta-sequestered parasites are known to more strongly adhere to CSA as opposed to CD36 [22, 42]. CSA-binding isolates were indeed shown to present a defect for non opsonic phagocytosis in vitro [43]. Importantly, placental pathology during malaria infection in mice has been reported to depend on a mitochondrial-dependent apoptotic pathway occurring through increased lipid peroxidation thus jeopardizing the materno-fetal relationship [44]. Considering that CD36 plays an important role in the non-inflammatory 

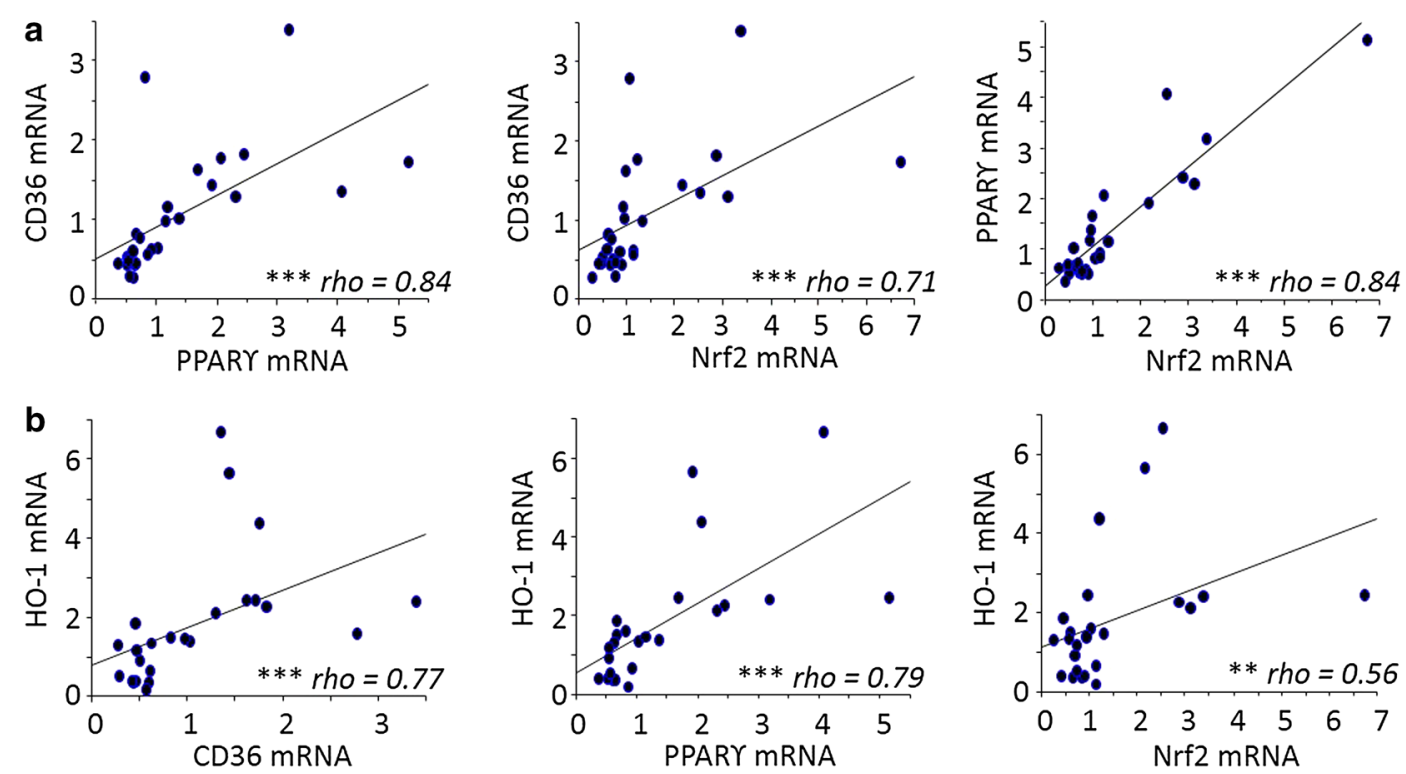

Fig. 3 Correlations between CD36, PPAR $\gamma$, Nrf2 and HO-1 mRNA levels expressed by monocytes sampled in Beninese women presenting malaria at delivery. a Correlations between CD36/PPAR $\gamma$, CD36/Nrf2 and PPAR $\gamma / \mathrm{Nrf2}$. b Correlations between HO-1/CD36, HO-1/PPAR $\gamma$ and HO-1/Nrf2. Statistical significance was tested by the Spearman correlation test. ${ }^{* *} \mathrm{P}<0.0005,{ }^{* *} \mathrm{P}<0.005,{ }^{*} \mathrm{P}<0.5$

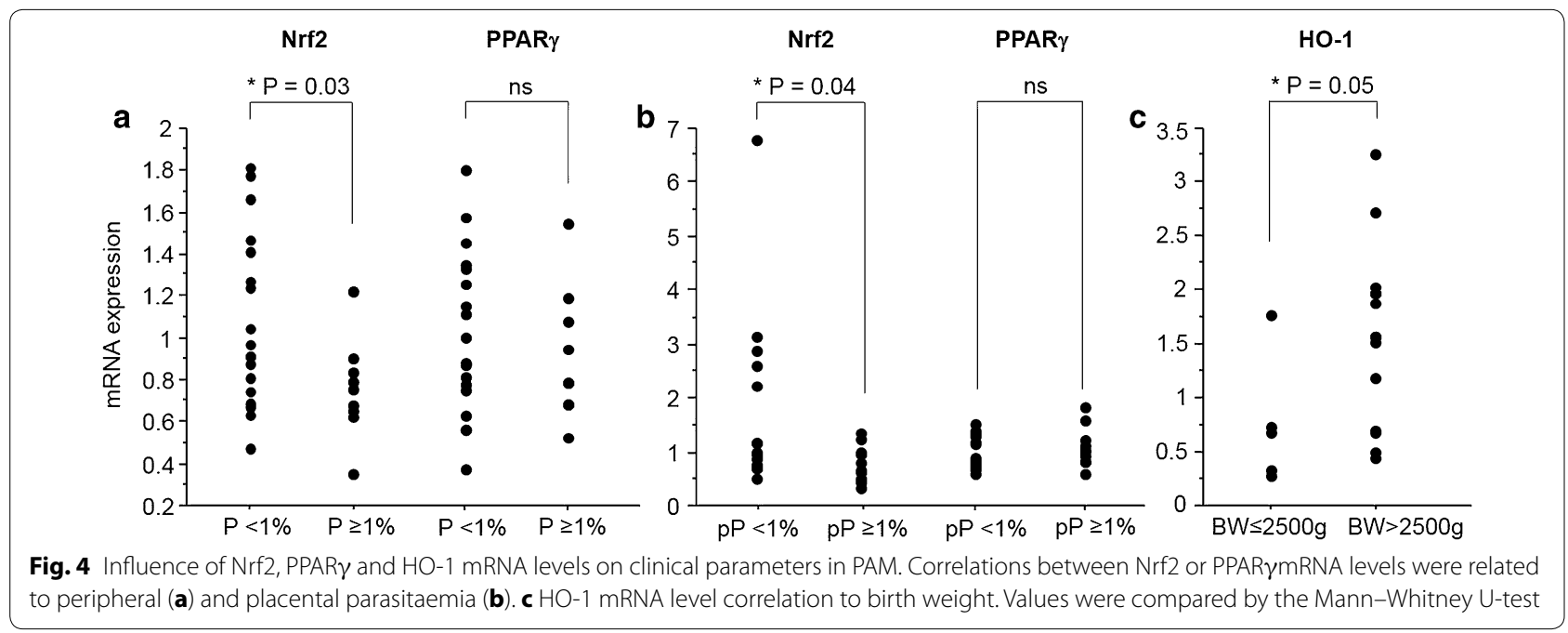

elimination of apoptotic cells [14], it is tempting to speculate that CD36 may also regulate the elimination of dead cells at the placental level during PAM, which would maintain feto-maternal exchanges and increase birth weight at delivery.

The other known function of CD36 during malaria infection includes its collaboration with TLR2 to trigger inflammatory response to $P f$-GPI anchors [19]. This should logically not correlate to higher birth weights as the inflammatory response in the placenta is thought to lead to low birth weight by damages caused to the placenta villi and the disturbance of feto-maternal exchanges $[6,45]$. In this study, birth weight was not related to cytokine levels, but an increase in IL-10 plasma levels was noticed in response to increased parasite densities which is in line with previous literature proposing IL-10 as a biomarker of $P$. falciparum infection during pregnancy [46]. Production of IL-10 during PAM may help in counteracting the consecutive damages of the inflammatory response. In a longitudinal study comparing uninfected and P. falciparum infected women during pregnancy, the increase of IL-10 level during PAM 


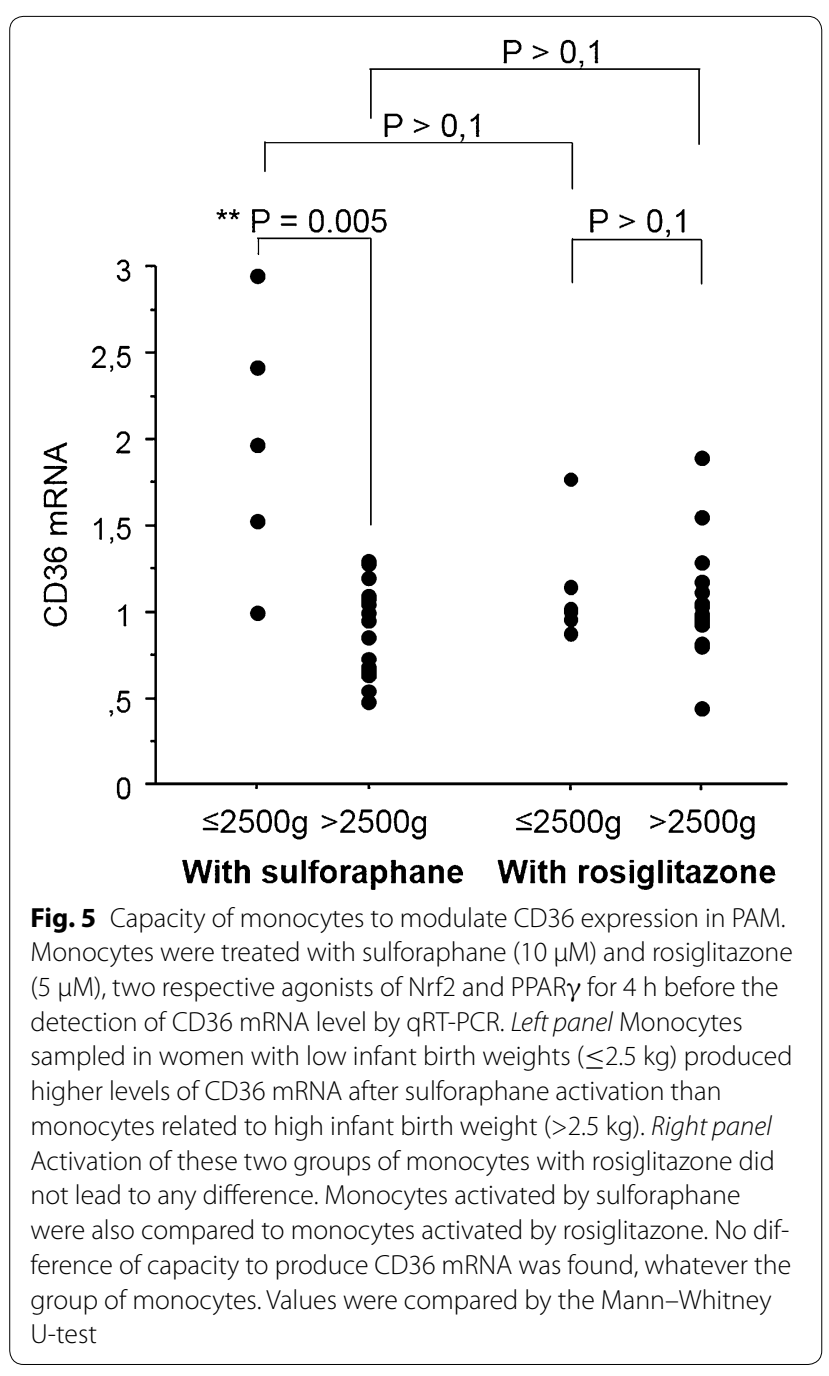

was combined to increased IP-10 level and decreased RANTES level regardless of gestational age at the time of infection [47]. RANTES, a chemokine implied in leucocyte recruitment at inflammatory sites, has been associated with severity and mortality in malaria children [48, 49]. In addition, RANTES production was shown to be IL-10-dependent in vitro [50]. IP-10 has also been identified as a biomarker for mortality in children with cerebral malaria [51] or severe malaria [52]. IL-10, IP-10 and RANTES are thus probably implied in the control of the pro- and anti-inflammatory balance, a key factor during PAM for limiting both infection and foetus damages.

Interestingly the CD36 scavenger receptor was strictly expressed by $\mathrm{CD} 14^{+} \mathrm{CD} 16^{-}$and $\mathrm{CD} 14^{+} \mathrm{CD} 16^{+}$monocytes, and its expression was extremely low in $\mathrm{CD} 14^{\text {low }}$ $\mathrm{CD} 6^{+}$monocytes. Intermediate monocytes $\left(\mathrm{CD} 14^{+}\right.$ $\mathrm{CD} 16^{+}$) are thought to be largely anti-inflammatory by producing high levels of IL-10 and increasing phagocytic activity [53]. The overexpression of CD36 on these cells would contribute to the former, however CD36-dependent phagocytosis may not be very relevant during PAM. On the other hand, CD36 and IL-10 mRNA levels in monocytes from this cohort were positively correlated, suggesting that CD36 expression was involved in an antiinflammatory process. The anti-inflammatory response during malaria also implies the receptor CD163 which scavenges the complex haemoglobin:haptoglobin, allows heme degradation by HO- 1 , avoids tissue damage [ 54 , 55], and facilitates IL-10 secretion [56].

The present work demonstrates a link between the transcription of CD36, CD163, HO-1 and IL-10 mRNA during PAM. CD36, Nrf2 and PPAR $\gamma$ were also related

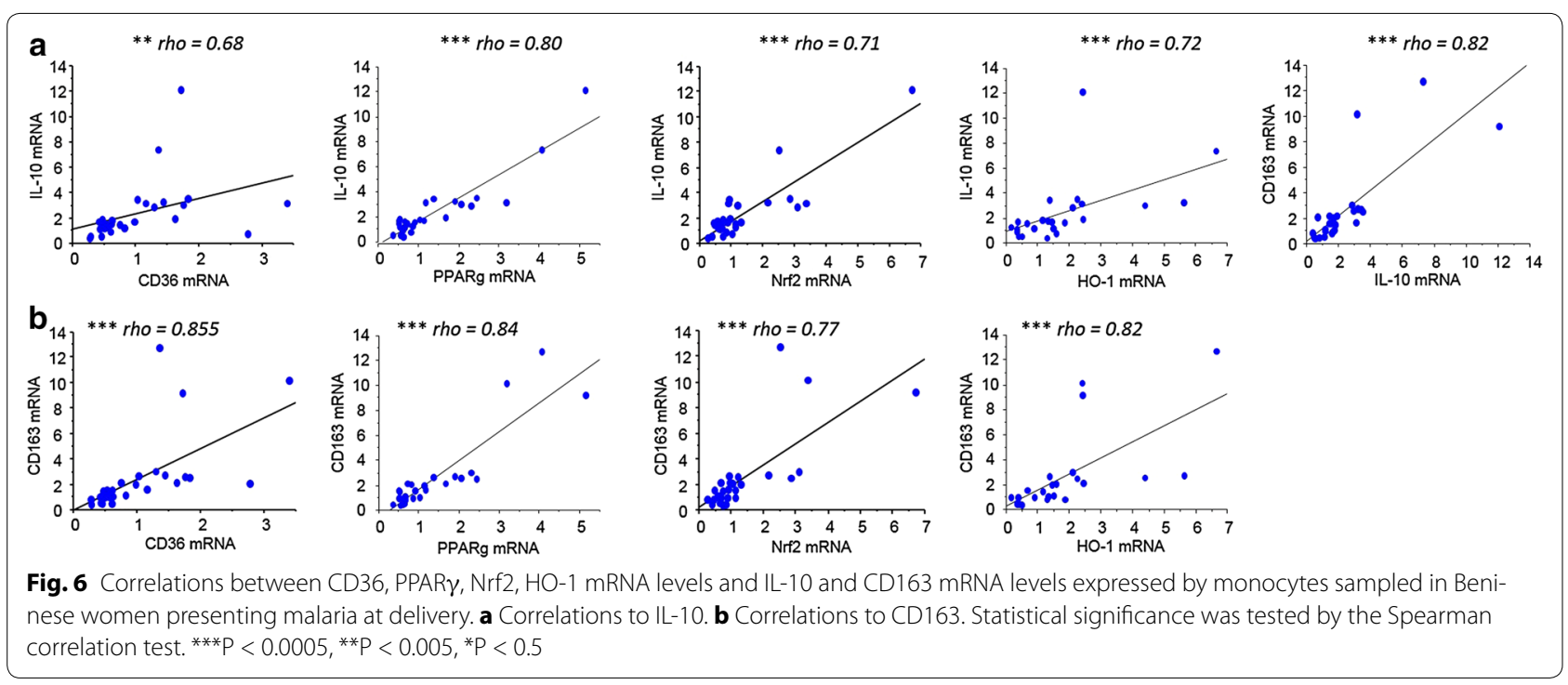


to CD163 expression, reinforcing the anti-inflammatory aspect of CD36 expression on monocytes. Chua et al. reported an association between the soluble form of CD163 (sCD163) and poor clinical outcomes during PAM, i.e. lower hemoglobin levels and lower infant birth weights compared to uninfected pregnant women [57]. sCD163 is the result of CD163 shedding induced by TNF [36]. sCD163 levels were shown to be inversely correlated to membrane-bound CD163, suggesting that high sCD163 levels may reflect lower membrane-bound CD163 activity [58]. These results combined with the present study suggest that a greater activity of membrane-bound CD163, or a higher expression of CD163 on the cell surface, would promote favorable clinical outcomes during PAM by limiting inflammation due to free hemoglobin and heme. This possibility, however, deserves further investigation.

Non-classical $\left(\mathrm{CD} 14^{\text {low }} \mathrm{CD}^{+} 6^{+}\right)$monocytes are described as the pro-inflammatory monocytes producing TNF and little or no IL-10 [59]. Interestingly, a low CD36 expression level was observed in these cells, which correlates with previous findings demonstrating that inflammatory processes, including TNF stimulation, dampens CD36 expression through an inhibition of PPAR $\gamma$ transcriptional activity [29]. These results support the notion that a CD14 ${ }^{+}$phenotype, tolerant to CD36 expression, are linked to beneficial outcomes during PAM. It can be also noted that $\mathrm{CD} 14+$ monocytes were largely predominant $(80.3 \%)$, despite a noteworthy increase of the non-classical monocyte population compared to healthy pregnancy (see Fig. 1b). CD36 expression may thus have a real impact even if its expression may be lowered compared to uninfected women. However, additional studies could help in understanding the sequence and interdependence of events such as Nrf2 activation, CD36 expression on monocytes, HO-1 and CD163 induction, and IL-10 production during PAM.

PPAR- $\gamma$ and Nrf2 transcription factors were both shown to regulate CD36 protein expression on monocytes $[24,25]$. Olagnier et al. demonstrated that in inflammatory conditions the stimulation of the Nrf2 pathway improved the outcome of severe malaria in mice, whereas PPAR $\gamma$ activation was only slightly active and much less efficient in inducing CD36 expression [29]. In addition, a previous report showed that circulating monocytes from malaria-infected patients presented decreased CD36 protein expression [60]. In this study, the capacity of circulating monocytes from PAM patients to modulate CD36 expression upon rosiglitazone or sulforaphane activation, two respective PPAR- $\gamma$ and Nrf2 agonists, was evaluated. Only sulforaphane activation induced monocytes from MoLBW to increase CD36 mRNA levels to those of MoHBW. This indicates that MoLBW do not have an impaired Nrf2 pathway, but likely lacked the appropriate stimulation in vivo. Nrf2 activators may be endogenous, particularly the products of oxidative stress (oxygen reactive species, lipid mediators), or exogenous, such as electrophile molecules (curcumin and sulforaphane for example). This result underlines the potential role of the Nrf2 pathway in limiting malaria severity during PAM.

Interestingly, this study showed that increased Nrf2 mRNA levels were associated with lower peripheral and placental parasitaemia during PAM, whereas no such relation was found for PPAR $-\gamma$ mRNA levels. Thus, it can be postulated that in this Beninese PAM context, the Nrf2 pathway, and not the PPAR- $\gamma$ pathway, is associated with limited parasite survival and proliferation. Nrf2 is a master regulator of the transcription of many antioxidant and detoxification enzymes, which are required to control the inflammatory process initiated by the detection and phagocytosis of malaria [30]. One such enzyme is HO-1 (encoded by the Hmox-1 gene), known for its role in heme detoxification during malaria by the catabolization of free heme into biliverdin, iron and carbon monoxide [61]. HO-1 was shown to have protective properties in an experimental cerebral malaria model $[32,33]$. In this manuscript, a correlation between high HO-1 mRNA levels in monocytes from MoHBW was established, confirming a beneficial role during PAM outcomes. However, recent data propose that high placental parasitaemia leads to an excessive activity of HO-1; intracellular iron accumulation and overload in trophoblasts, inducing cell death and impairing fetal development [62]. Altogether, this suggests that Nrf2 plays a central role in defining the balance between pro- and anti-oxidant mechanisms that appears essential for both infection elimination and host protection.

\section{Conclusions}

This work demonstrates the role of the CD36 scavenger receptor, the enzyme $\mathrm{HO}-1$ and the anti-oxidant pathway Nrf2 in protection against the pathology of malaria during pregnancy. Whereas the antioxidant and detoxifying effects of Nrf2-dependent HO-1 corroborate with other published data, the function of CD36 expression on monocytes during PAM needs further clarification. The positive association of CD36 in PAM clinical outcomes deserves corroboration in other populations and studies, including a larger group of mothers with low birth weight infants.

\section{Additional file}

Additional file 1: Table S1. Human primer sequences used in quantitative PCR experiments. 


\section{Authors' contributions}

$A A, D O, A C$, and $B P$ conceived the study and experiments. PD, GB, SE, and AM organized and supervised the patients enrolment, sampling and provided clinical and parasitological data analysis. AA, CM and SM carried out all the laboratory experiments. AA and DO drafted the manuscript. All authors helped to finalize the manuscript. All authors read and approved the final manuscript.

\section{Author details}

${ }^{1}$ Institut de Recherche pour le Développement (IRD), Université Paul Sabatier Toulouse III, UMR 152 Pharma-Dev, CHU Rangueil, Bâtiment L1, 1 Avenue du Pr Jean Poulhès, 31059 Toulouse, France. ${ }^{2}$ Institut de Recherche pour le Développement (IRD), PRES Sorbonne Paris Cité, Université Paris Descartes, UMR 216 Mère et enfant face aux infections tropicales, Paris, France. ${ }^{3}$ Centre d'Etude et de Recherche sur le Paludisme Associé à la Grossesse et l'Enfance (CERPAGE), Cotonou, Benin. ${ }^{4}$ Present Address: Lady Davis Institute-Jewish General Hospital, McGill University, Montreal, Canada. ${ }^{5}$ Present Address: Laboratoire Insulaire du Vivant et de l'Environnement (LIVE-EA 4243), Université de la NouvelleCaledonie (UNC), Nouméa, New Caledonia.

\section{Acknowledgements}

We would like to thank Alexandre Sze for his careful reading and editing of the manuscript. We are grateful to Professor Blaise Ayivi, chief of Paediatrics at CNHU in Cotonou, Jules M Alao, Gratien Sagbo and Francis Lalya, paediatricians, for their support and assistance renewed for patient enrolment. We also thank Nadine Fievet for help in the collection of samples. We thank Christiane Pecher and Alexias Zakaroff-Girard from the cytometry technical platform (Rangueil Hospital, Toulouse) for their kind help for cytometry analysis.

\section{Compliance with ethical guidelines}

\section{Competing interests}

The authors declare they have no competing interests.

Received: 22 May 2015 Accepted: 3 September 2015 Published online: 18 September 2015

\section{References}

1. WHO. World malaria report. World Health Organization, Geneva, Switzerland. 2013.

2. Desai M, ter Kuile FO, Nosten F, McGready R, Asamoa K, Brabin B, et al. Epidemiology and burden of malaria in pregnancy. Lancet Infect Dis. 2007;7:93-104.

3. Beeson JG, Amin N, Kanjala M, Rogerson SJ. Selective accumulation of mature asexual stages of Plasmodium falciparum-infected erythrocytes in the placenta. Infect Immun. 2002;70:5412-5.

4. Rogerson SJ, Hviid L, Duffy PE, Leke RF, Taylor DW. Malaria in pregnancy: pathogenesis and immunity. Lancet Infect Dis. 2007;7:105-17.

5. Rogerson SJ, Pollina E, Getachew A, Tadesse E, Lema VM, Molyneux ME. Placental monocyte infiltrates in response to Plasmodium falciparum malaria infection and their association with adverse pregnancy outcomes. Am J Trop Med Hyg. 2003;68:115-9.

6. Menendez C, Ordi J, Ismail MR, Ventura PJ, Aponte JJ, Kahigwa E, et al. The impact of placental malaria on gestational age and birth weight. J Infect Dis. 2000;181:1740-5.

7. Ismail MR, Ordi J, Menendez C, Ventura PJ, Aponte JJ, Kahigwa E, et al. Placental pathology in malaria: a histological, immunohistochemical, and quantitative study. Hum Pathol. 2000;31:85-93.

8. Fried M, Muga RO, Misore AO, Duffy PE. Malaria elicits type 1 cytokines in the human placenta: IFN-gamma and TNF-alpha associated with pregnancy outcomes. J Immunol. 1998;160:2523-30.

9. Rogerson SJ, Brown HC, Pollina E, Abrams ET, Tadesse E, Lema VM, et al. Placental tumor necrosis factor alpha but not gamma interferon is associated with placental malaria and low birth weight in Malawian women. Infect Immun. 2003;71:267-70.

10. McDevitt MA, Xie J, Shanmugasundaram G, Griffith J, Liu A, McDonald $C$, et al. A critical role for the host mediator macrophage migration inhibitory factor in the pathogenesis of malarial anemia. J Exp Med. 2006:203:1185-96.
11. Singh PP, Lucchi NW, Blackstock A, Udhayakumar V, Singh N. Intervillous macrophage migration inhibitory factor is associated with adverse birth outcomes in a study population in Central India. PLoS One. 2012;7:e51678

12. Stevenson MM, Riley EM. Innate immunity to malaria. Nat Rev Immunol. 2004;4:169-80.

13. Mac-Daniel L, Menard R. Plasmodium and mononuclear phagocytes. Microb Pathog. 2015;78:43-51.

14. Silverstein RL, Febbraio M. CD36, a scavenger receptor involved in immunity, metabolism, angiogenesis, and behavior. Sci Signal. 2009;2:re3.

15. Trinchieri $\mathrm{G}$, Sher A. Cooperation of Toll-like receptor signals in innate immune defence. Nat Rev Immunol. 2007;7:179-90.

16. McGilvray ID, Serghides L, Kapus A, Rotstein OD, Kain KC. Nonopsonic monocyte/macrophage phagocytosis of Plasmodium falciparumparasitized erythrocytes: a role for CD36 in malarial clearance. Blood. 2000;96:3231-40.

17. Patel SN, Serghides L, Smith TG, Febbraio M, Silverstein RL, KurtzTW, et al. CD36 mediates the phagocytosis of Plasmodium falciparum-infected erythrocytes by rodent macrophages. J Infect Dis. 2004;189:204-13.

18. Serghides L, Kain KC. Peroxisome proliferator-activated receptor gammaretinoid $X$ receptor agonists increase $C D 36$-dependent phagocytosis of Plasmodium falciparum-parasitized erythrocytes and decrease malariainduced TNF-alpha secretion by monocytes/macrophages. J Immunol. 2001;166:6742-8.

19. Patel SN, Lu Z, Ayi K, Serghides L, Gowda DC, Kain KC. Disruption of CD36 impairs cytokine response to Plasmodium falciparum glycosylphosphatidylinositol and confers susceptibility to severe and fatal malaria in vivo. J Immunol. 2007;178:3954-61.

20. Zhu J, Wu X, Goel S, Gowda NM, Kumar S, Krishnegowda G, et al. MAPK-activated protein kinase 2 differentially regulates Plasmodium falciparum glycosylphosphatidylinositol-induced production of tumor necrosis factor-alpha and interleukin-12 in macrophages. J Biol Chem. 2009;284:15750-61.

21. Ockenhouse CF, Tandon NN, Magowan C, Jamieson GA, Chulay JD. Identification of a platelet membrane glycoprotein as a falciparum malaria sequestration receptor. Science. 1989;243:1469-71.

22. Fried M, Duffy PE. Adherence of Plasmodium falciparum to chondroitin sulfate A in the human placenta. Science. 1996;272:1502-4.

23. Doritchamou J, Sossou-tchatcha S, Cottrell G, Moussiliou A, Hounton Houngbeme C, Massougbodji A, et al. Dynamics in the cytoadherence phenotypes of Plasmodium falciparum infected erythrocytes isolated during pregnancy. PLoS One. 2014;9:e98577.

24. Nicholson AC. Expression of CD36 in macrophages and atherosclerosis: the role of lipid regulation of PPARgamma signaling. Trends Cardiovasc Med. 2004;14:8-12.

25. Maruyama A, Tsukamoto S, Nishikawa K, Yoshida A, Harada N, Motojima $\mathrm{K}$, et al. Nrf2 regulates the alternative first exons of CD36 in macrophages through specific antioxidant response elements. Arch Biochem Biophys. 2008:477:139-45.

26. Atamna $\mathrm{H}$, Ginsburg $\mathrm{H}$. Origin of reactive oxygen species in erythrocytes infected with Plasmodium falciparum. Mol Biochem Parasitol. 1993;61:231-41.

27. Bilban M, Bach FH, Otterbein SL, Ifedigbo E, d'Avila JC, Esterbauer H, et al. Carbon monoxide orchestrates a protective response through PPARgamma. Immunity. 2006;24:601-10.

28. Yamamoto T, Suzuki T, Kobayashi A, Wakabayashi J, Maher J, Motohashi H, et al. Physiological significance of reactive cysteine residues of Keap1 in determining Nrf2 activity. Mol Cell Biol. 2008;28:2758-70.

29. Olagnier D, Lavergne RA, Meunier E, Lefèvre L, Dardenne C, Aubouy A, et al. Nrf2, a PPAR- $\gamma$ alternative pathway to promote CD36 expression on inflammatory macrophages: implication for malaria. PLoS Pathog. 2011;7:e1002254.

30. Deramaudt TB, Dill C, Bonay M. Regulation of oxidative stress by Nrf2 in the pathophysiology of infectious diseases. Med Mal Infect. 2013;43:100-7.

31. Ferreira A, Balla J, Jeney V, Balla G, Soares MP. A central role for free heme in the pathogenesis of severe malaria: the missing link? J Mol Med (Berl). 2008:86:1097-111.

32. Pamplona A, Ferreira A, Balla J, Jeney V, Balla G, Epiphanio S, et al. Heme oxygenase-1 and carbon monoxide suppress the pathogenesis of experimental cerebral malaria. Nat Med. 2007:13:703-10. 
33. Jeney V, Ramos S, Bergman ML, Bechmann I, Tischer J, Ferreira A, et al. Control of disease tolerance to malaria by nitric oxide and carbon monoxide. Cell Rep. 2014;8:126-36.

34. Walther M, De Caul A, Aka P, Njie M, Amambua-Ngwa A, Walther B, et al. HMOX 1 gene promoter alleles and high $\mathrm{HO}-1$ levels are associated with severe malaria in Gambian children. PLoS Pathog. 2012;8:e1002579.

35. Clark IA, Awburn MM, Harper CG, Liomba NG, Molyneux ME. Induction of $\mathrm{HO}-1$ in tissue macrophages and monocytes in fatal falciparum malaria and sepsis. Malar J. 2003;2:41.

36. Etzerodt A, Moestrup SK. CD163 and inflammation: biological, diagnostic, and therapeutic aspects. Antioxid Redox Signal. 2013;18:2352-63.

37. Bertin Gl, Lavstsen T, Guillonneau F, Doritchamou J, Wang CW, Jespersen JS, et al. Expression of the domain cassette 8 Plasmodium falciparum erythrocyte membrane protein 1 is associated with cerebral malaria in Benin. PLoS One. 2013;8:e68368.

38. Ziegler-Heitbrock L, Ancuta P, Crowe S, Dalod M, Grau V, Hart DN, et al. Nomenclature of monocytes and dendritic cells in blood. Blood. 2010;116:e74-80

39. Brabin BJ, Romagosa C, Abdelgalil S, Menéndez C, Verhoeff FH, McGready $R$, et al. The sick placenta — the role of malaria. Placenta. 2004;25:359-78.

40. Dorman EK, Shulman CE, Kingdom J, Bulmer JN, Mwendwa J, Peshu N, et al. Impaired uteroplacental blood flow in pregnancies complicated by falciparum malaria. Ultrasound Obstet Gynecol. 2002;19:165-70.

41. Imamura T, Sugiyama T, Cuevas LE, Makunde R, Nakamura S. Expression of tissue factor, the clotting initiator, on macrophages in Plasmodium falciparum-infected placentas. J Infect Dis. 2002;186:436-40.

42. Achur RN, Valiyaveettil M, Alkhalil A, Ockenhouse CF, Gowda DC. Characterization of proteoglycans of human placenta and identification of unique chondroitin sulfate proteoglycans of the intervillous spaces that mediate the adherence of Plasmodium falciparum-infected erythrocytes to the placenta. J Biol Chem. 2000;275:40344-56.

43. Serghides L, Patel SN, Ayi K, Kain KC. Placental chondroitin sulfate A-binding malarial isolates evade innate phagocytic clearance. J Infect Dis. 2006;194:133-9.

44. Sharma L, Kaur J, Shukla G. Role of oxidative stress and apoptosis in the placental pathology of Plasmodium berghei infected mice. PLoS One. 2012;7:e32694.

45. Ordi J, Ismail MR, Ventura PJ, Kahigwa E, Hirt R, Cardesa A, et al. Massive chronic intervillositis of the placenta associated with malaria infection. Am J Surg Pathol. 1998;22:1006-11.

46. Chêne A, Briand V, Ibitokou S, Dechavanne S, Massougbodji A, Deloron $P$, et al. Placental cytokine and chemokine profiles reflect pregnancy outcomes in women exposed to Plasmodium falciparum infection. Infect Immun. 2014;82:3783-9.

47. Boström S, Ibitokou S, Oesterholt M, Schmiegelow C, Persson JO, Minja D, et al. Biomarkers of Plasmodium falciparum infection during pregnancy in women living in northeastern Tanzania. PLoS One. 2012;7:e48763.

48. Ochiel DO, Awandare GA, Keller CC, Hittner JB, Kremsner PG, Weinberg JB, et al. Differential regulation of beta-chemokines in children with Plasmodium falciparum malaria. Infect Immun. 2005;73:4190-7.

49. John CC, Opika-Opoka R, Byarugaba J, Idro R, Boivin MJ. Low levels of RANTES are associated with mortality in children with cerebral malaria. J Infect Dis. 2006;194:837-45.
50. Were T, Davenport GC, Yamo EO, Hittner JB, Awandare GA, Otieno MF, et al. Naturally acquired hemozoin by monocytes promotes suppression of RANTES in children with malarial anemia through an IL-10-dependent mechanism. Microbes Infect. 2009;11:811-9.

51. Erdman LK, Dhabangi A, Musoke C, Conroy AL, Hawkes M, Higgins S, et al. Combinations of host biomarkers predict mortality among Ugandan children with severe malaria: a retrospective case-control study. PLoS One. 2011;6:e17440

52. Armah HB, Wilson NO, Sarfo BY, Powell MD, Bond VC, Anderson W, et al. Cerebrospinal fluid and serum biomarkers of cerebral malaria mortality in Ghanaian children. Malar J. 2007:6:147.

53. Skrzeczyńska-Moncznik J, Bzowska M, Loseke S, Grage-Griebenow E, Zembala M, Pryjma J. Peripheral blood CD14high CD16+ monocytes are main producers of IL-10. Scand J Immunol. 2008;67:152-9.

54. Sadrzadeh SM, Graf E, Panter SS, Hallaway PE, Eaton JW. Hemoglobin. A biologic fenton reagent. J Biol Chem. 1984;259:14354-6.

55. Philippidis P, Mason JC, Evans BJ, Nadra I, Taylor KM, Haskard DO, et al. Hemoglobin scavenger receptor CD163 mediates interleukin-10 release and heme oxygenase-1 synthesis: antiinflammatory monocytemacrophage responses in vitro, in resolving skin blisters in vivo, and after cardiopulmonary bypass surgery. Circ Res. 2004;94:119-26.

56. Yunoki K, Inoue T, Sugioka K, Nakagawa M, Inaba M, Wada S, et al. Association between hemoglobin scavenger receptor and heme oxygenase1-related anti-inflammatory mediators in human coronary stable and unstable plaques. Hum Pathol. 2013;44:2256-65.

57. Chua CL, Brown GV, Hamilton JA, Molyneux ME, Rogerson SJ, Boeuf P. Soluble CD163, a product of monocyte/macrophage activation, is inversely associated with haemoglobin levels in placental malaria. PLoS One. 2013;8:e64127.

58. Davis BH, Zarev PV. Human monocyte CD163 expression inversely correlates with soluble CD163 plasma levels. Cytom B Clin Cytom. 2005;63:16-22.

59. Belge KU, Dayyani F, Horelt A, Siedlar M, Frankenberger M, Frankenberger $B$, et al. The proinflammatory CD14+CD16+DR++ monocytes are a major source of TNF. J Immunol. 2002;168:3536-42

60. Berry A, Chene G, Benoit-Vical F, Lepert JC, Bernad J, Marchou B, et al. Ex vivo and in vitro impairment of CD36 expression and tumor necrosis factor-alpha production in human monocytes in response to Plasmodium falciparum-parasitized erythrocytes. J Parasitol. 2005;91:316-22.

61. Tenhunen R. The enzymatic degradation of heme. Semin Hematol. 1972;9:19-29

62. Penha-Gonçalves C, Gozzelino R, de Moraes LV. Iron overload in Plasmodium berghei-infected placenta as a pathogenesis mechanism of fetal death. Front Pharmacol. 2014:5:155.

63. Bardou M, Hadi T, Mace G, Pesant M, Debermont J, Barrichon M, et al. Systemic increase in human maternal circulating CD14+ CD16- MCP-1+ monocytes as a marker of labor. Am J Obstet Gynecol. 2014;210:70.e1-9.

\section{Submit your next manuscript to BioMed Central and take full advantage of:}

- Convenient online submission

- Thorough peer review

- No space constraints or color figure charges

- Immediate publication on acceptance

- Inclusion in PubMed, CAS, Scopus and Google Scholar

- Research which is freely available for redistribution

Submit your manuscript at

www.biomedcentral.com/submit

C BioMed Central 